\title{
SOCIO-ECONOMIC DUALISM IN THE DEVELOPMENT PROCESS WITH PARTICULAR REFERENCE TO WOMEN, WORK AND FAMILY
}

\author{
K.G. Uma*
}



\section{ABSTRACT}

Women are slowly breaking the traditional bondages and slowly challenging the male bastion of power. Empowerment of women is a precondition for women's liberation. Family relationships have a direct bearing on women's professional role. The author states that there has to be a blend of women's special role in the socio-economic gender equations vis-a-vis different job dimensions.

\section{Introduction}

A silent revolution has produced women professionals of high calibre in Indian society. Crossing the barriers of several socio-cultural restrictions, Indian women excel in their professions, demonstrating their ability, genius and inner worth. This dynamic change has affected the status of women, giving it a fresh dignity and

\footnotetext{
* Director, Centre for Women's Studies, Bangalore University, Bangalore - 560056, India.
} 
importance. The recognition of the right of women to compete equally with men opened up new pathways of service and encourages women to play an increasingly effective role, in public affairs as professionals.

Today we have a galaxy of distinguished and brilliant women professionals who have achieved a staggering success in their professions.

As a result, in Indian society attitudes are changing. Upon the dignity and competence of women rests the development of our nation.

Recent years have brought a great change in the life of women all over the world, influencing their attitudes, values, aspirations, ways of feeling and acting, thus expanding the role of a housewife into a dominant and mature feminine role through employment. In our country, various social changes have affected the urban educated population in general and the women of middle class in particular. Urbanisation, education and employment are the contributions of social evolution. One of the more enduring consequences of the recent social evolution for women has been their emancipation from their tradition bound ethos both legally and politically by the virtue of various acts and statutes.

By coming out of their homes in the gainful employment, women have broken the traditional notion that working outside is derogatory to them or that only under gross economic necessity they can work outside homes. Thus a social change involving the second sex in the economic development of the society has begun.

A profession certainly empowers women to some extent and certainly is one of the preconditions for women's liberation. But to what extent has it really liberated women is an important issue worth pondering on. In this context, we need to analyse the gender based inequalities which exist due to prevailing social norms, values and stereotypes ascribing an inferior status to women and the role of profession in uplifting women.

Most of the studies on women have stressed the impact of work role on the family but neglected the impact of family on work. Discussions of women work role are meaningful only in the background of the home institution. Though both men and women participate in the work organisation, the impact and influence of home on work role differ significantly. The bond between home and women is more intense than that between men and home and this is fundamental to the analysis of women's work role.

This study is unique in this regard by giving equal importance to the influence and impact of both the factors - home and work on each other. This gives a well 
balanced view of women professionals in terms of their status and role at home and work.

Also this study endeavours to provide a kaleidoscopic view on women's work and familial roles by adopting a wide range of professions. Most of the earlier studies have attempted to study only one group in detail, or a comparison of two or three groups of professionals. This study has included five groups of professionals in order to have wider knowledge and a comprehensive approach.

Problem: Women professionals are new prototypes and their families are new structures and both are in transition. This transition requires sociological analyses. The impact of the newly achieved economic role of liberation of women from inequalities constitutes the central theme.

Universe and Sample: Among the women professionals of Bangalore, 300 women belonging to a wide range of five professions - college teachers, doctors, engineers, lawyers and executives - were chosen for the study.

Sampling Technique: Purposive sampling technique has been adopted with 60 women in each profession and equal representation from Hindus, Muslims and Christians.

Tool: The interview schedule, which has been pre-tested in a pilot study to enhance its validity has been used.

\section{Research Setting}

The five groups of women professional constitute the research setting of the present study. Bangalore, the capital of Karnataka, is a modern bustling city and an important industrial centre. It is a cosmopolitan centre and one of India's most progressive and liberal cities as far as social attitudes are concerned. Being a westernized Indian city, Bangalore offers an encouraging atmosphere for women to take up modern professions. The prevailing socio-cultural condition in Bangalore is an important influence on women to cross the sex barriers and enter the male territories in the occupational system. Hence Bangalore is chosen as the research setting.

\section{Major Findings}

The socio-economic background of women professionals reveals that most of the respondents belong to the age group of 21-30 years. This is due to the fact that the 
entrance of women in modern professions is a recent phenomenon. The caste composition of the data reveals that women belonging to various castes are taking up different professions. But the dominance of high castes still prevails. Inspite of the reservation policy and special concessions, only very few women have taken up modern professions. Most of the women in the study are married and only a very few are divorced or separated. This reveals that women are able to successfully combine marriage and career - the two mutually opposing roles. It is an encouraging scenario because inspite of the incompatibility of the role obligations of work and family, many married women are able to combine their two roles, though it involves many constraints and conflicts. It also reveals that economic independence of women has not favoured divorce in the Indian context - a situation far from the western trend. As compared to other professionals, higher rate of divorce is observed among executives. This may be an indication of their individualism and affluent occupational culture. Religion based analysis shows that most of Muslim women in our sample belong to the age group of 21-30 years. This reveals their late entry into professions. This is due to the attitude towards girls' education prevailing in the Muslim community for a long time. Being an orthodox community with conservative outlook and unfavourable socio-cultural practices such as pardah system, early marriage, etc., and also due to their parent's high concentration in business rather than in professions, Muslim girls in India have not been exposed to higher education, especially professional courses. It is very obvious that their presence in the male dominated professions is very negligible. However, it is encouraging to see urban Muslim girls being slowly exposed to higher education and modern professions. The study also reveals that the entry of rural women into modern professions is a very limited phenomenon. The analysis of the data reveals that modern professions are exclusively confined to urban women. Therefore it may be inferred that a comparatively open structure of the urban society coupled with changing trends in socialization practices and access to higher education - especially professional courses, is responsible for urban women's entry into modern professions.

The composition and structure of households influences a number of issues relating to the family such as decision-making, child care, house work, marital harmony, etc. The analysis of the data reveals that an overwhelming majority of female professionals belong to nuclear families. It may be inferred that nuclear families are favourable for women's independent decision to work. Also nuclear families are more in number in Bangalore - a rapidly growing city with increasing industrialization, indicating the shattering effects of urbanization and industrialization on the joint family system. Most of the women professionals in the study have small families with one or two children. This reveals the impact of higher education and employment on the demographic trends. It is interesting to note that among the childless couples, the executives top the list. It may be inferred that a modern male 
dominated profession of an executive demands high level role expectation and therefore they may not prefer any interference in it due to family obligations. In a traditional Indian society where child bearing is a major social obligation, if a profession helps a woman to have control over her fertility and motherhood, then we can claim this as liberation from traditionalism. Feminist writers Adrienne Rich and Shulamith Firestone observed that biological motherhood, as it has been institutionalized under patriarchy is definitely something from which women must be liberated. In fact the researcher during her interviews with the respondents came across the practice of willingly abstaining from parenthood - a self imposed practice by a few couples - the emergence of a significant change in the traditional trend.

The educational status of our respondents reveals that a significant number of them possess more than the required minimum qualification. It is an encouraging scene to find some of the women professionals taking up higher education after marriage as this reveals that marriage, child bearing, child rearing and domestic obligations have not hampered their aspirations for an upward occupational mobility. In case of women teachers who possessed Ph.D qualification, most of their husbands had only professional degree or post graduation. Also a majority of our respondents have a higher income of above Rs. 10,000 per month, almost equal to that of their husbands.

The comparison of women's occupational status with that of their husbands reveals that a majority of our respondents have married men of equal or higher educational and occupational status, which in turn indicates a high level husband-wife status congruency. Further analysis based on profession reveals that a significant number of doctors, engineers and lawyers have married men of the same professions. This choice suggests a desire for greater harmony in the family and occupational roles of the wife and husband.

The socio-economic background of the parents reveal that most of our respondents belong to educated families as a whole. Among the parents in general, fathers are more educated than the mothers. It reveals the significant role of the educated parents in the socialization of girls to take up modern and male dominated professions. We see a very strong support system in the case of educated parents favourable for women to enter the male dominated professions. Also a significant number of our respondents having role models among the family members indicate the transmission of achievement values through aspirations emphasizing the role of family as a great socializer. The highest proportion of our respondents belongs to middle class families. It reveals that middle class families with good educational and economic background provide conducive atmosphere as well as incentives and motivation for the younger generation to enter into the more challenging and 
specialized professions of high prestige. It is by and large, a reflection of the typical middle class ideology which wants security, prestige and a fixed income through a profession.

Women's professional role now carries with it the approval of culture conformity a trend which was not allowed by our culture earlier for several centuries. The analysis of the data reveals that women are becoming more conscious of spending their time fruiffully by taking up a profession of their choice. The data also reveal that a majority of our respondents belong to middle class families with good educational background. Parents' education and occupations provide a very strong support system for the girls to enter into more challenging and specialized professions of high prestige. A significant proportion of our respondents having role models among the family members emphasize the role of the family as a great socializer. Thus the first hypothesis - the choice of various professions is influenced by support systems and economic, psychological, social and cultural factors rather than academic interest aptitude and skills - has been proved to be true by the present study.

Job satisfaction is the result of various attitudes. An analysis of job satisfaction reveals that a majority of our respondents have a high level job satisfaction while a minority have moderate level job satisfaction. Only a few of our respondents are not satisfied with their jobs.

Career commitment symbolizes a complex form of human behaviour resulting from the interplay of several forces - human, organizational and social which vary in intensity but are operative at the same time. An analysis of the career commitment of our respondents reveal that most of them do have a higher degree of commitment while some of them have moderate degree of commitment. Without sufficient level of career commitment it is impossible to compete with men in prestigious male dominated professions to which majority of our respondents belong.

Occupational success is directly related to the quality of role performance which comies up to the expectations of the role definers. It is anchored in subjective as well as objective conditions. The study reveals that a majority of our respondents claimed only moderate degree of occupational success, which is due to the fact that most of our respondents are competing with men in male dominated professions in equal and uncompromising terms with a heavy burden of dual role.

Job salience refers to whether the earning role is being perceived by working women as being secondary to their principal role of home making or earning role is perceived as equal to homemaking or whether earning role has priority over and above the family role. An analysis of job salience reveals that a majority of our respondents 
are having moderate job salience by giving equal priority for both is a welcome trend. In a traditional society where the primacy of the family role is predominant, a change in attitude indicates the emergence of a new social trend among many women professionals of the present study. The second larger proportion of our respondents, having low job salience indicates the lower hierarchic location of the job role in preference for the family role. It is quite natural in a patriarchal society where man is the 'provider', women's newly acquired economic role does not bring a drastic change in this trend as she is considered as only the 'co-provider'. A few of our respondents having high job salience with priority for job role reveals the presence of strong support and cooperation of family members without which it is not possible.

To understand women's work dimensions, the crucial role of the socio-cultural context within which these women work and live must be recognized. The world of work is not isolated; rather it is an extension of the working day to accommodate both the roles. Family relationships have a direct bearing on women's professional role.

Similarly the work role demands compromises in family life. These compromises include neglect of family obligations, neglect of children, neglect of one's own health, considerable decrease in leisure and socializing etc. This is mainly because, a wife's profession has not resulted in a universal change of attitudes towards gender related issues among their husbands.

According to many scholars, male dominance could be possible on account of his active economic role. While analysing the impact of women's new economic role on the decision making process and authority structure, our data indicate that although an egalitarian trend is emerging in the decision making process, the power of the patriarch is still prevailing. Even in the case of wives who have equal occupational status and income in the present study, their men expect women to subordinate their career interests and personal aspirations to those of their husbands. The study also reveals that men are reluctant to give up their patriarchal privileges to 'share the housework.

Considering the relative power structure and prevailing trends, the present study explodes the myth that an active economic status and role would liberate a woman from inequalities and oppression and elevate her to an equal status. Just as education has not allowed for progressive values or the right to vote has not always meant access to decision making, likewise a profession does not really liberate a woman fully. The analysis of the data proves our hypothesis that in the family's authority structure and division of labour the traditional masculine-feminine dichotomy is 
not altered by women's professional siatus. The prevailing prejudices, sex role stereotypes, discrimination and marginalization in our work organizations and the burden of dual role, high intensity of role conflict, the patriarchal privileges in the sexual division of labour at home and decision making processes and power structure of the family clearly prove our hypothesis that professional status helps in empowering women to some extent and certainly is one of the preconditions for women's liberation.

However, a profession certainly empowers a woman. Having a profession means a sense of autonomy, self-respect, being mentally alert, a sense of fulfillment, economic security, status and prestige and experiencing a sense of worth and meaning in life.

Although the male point of view is included in the study on a small scale by interviewing the husbands of some of the respondents, men are not included in the sample. Explorations in male point of view may be undertaken in a detailed manner in future. However most of the husbands expressed a favourable attitude to their wives professional role and status.

Women's employment should not be under estimated. The numerous benefits of employment to women, families and nation should be acknowledged by the policy makers. Women constitute half of the population. Exclusion of women from active economic life due to sex role stereotype, discrimination and marginalization deprive the economy an immense reserve of human resources. Employment of women should be encouraged by the government. Work pre-training courses by local employment offices of Denmark, Austria's public information campaigns about the availability of vocational training and guidance in public places frequented by women and Sweden's efforts to promote equality of opportunity and treatment and the Russian model of vocational training at school level are some of the models to be emulated.

Status of women is an important index of the progress of a nation. Women are the only example of a majority being relegated to the fringe of society. The main characteristic of this status is a fundamental ambiguity between theoretical equality of rights enshrined in the Constitution and discriminations followed in reality. We need a sound policy to integrate women more fully in society generally and in employment in particular through reservation policy. The problems arising from legal, social, economic and political status of women in contemporary society are interdependent and cannot be arbitrarily separated. Hence we need a comprehensive policy which should be implemented sincerely. Such a policy should include an accent on compulsory education, application of dynamic vocational training and guidance for girls even at the school, educational reforms at higher levels with more emphasis on job oriented courses, creation of quotas for women at various 
levels of occupational hierarchy, equal sharing of expenses of wedding and establishment of home, adoption of legislations and regulations to do away with discriminations and effective machinery to check the incorporation of such legislations and regulations by the various organisations.

The failure of the newly achieved economic status in contributing to gender equality both in the family and work organisation is due to the structural conditions, cultural prescriptions and deep rooted social attitudes. The hierarchical relations between men and women are part of a patriarchal culture, entrenched in the social structure, reinforced by customs, traditions and religion. These have deep roots in the consciousness of most women and of nearly all men. As revealed by the study, although the entire family benefits from women's economic contribution, the problem of combining family and work is a concern of only women and not of men. Women alone suffer from the consequences. This crisis is subtle and dangerous. It must be resolved by creating a social climate favouring gender equality through the process of gender sensitization. The gender based roles should be weeded out from the society with the active role of mass media, women's wing of political parties, educational organisations and female pressure groups. Legal reforms in this regard including uniform civil code and legislations to end the discriminatory practices at all levels should be introduced.

There is an urgent need for a profound change in the attitudes. The stratification built on sex linked boundaries and gender based attitudes should be destroyed. We need rethinking, reorientation and restructuring of the institutionalized mode of interactions. Introduction of women's studies, in formal education at all levels for boys and girls and inculcation of values of gender equality and mutual respect through the non formal methods of mass media will usher in a new social order. Children are not born with knowledge about gender stereotypes but learn about them as they grow. If they are subjected to gender sensitization process with continuous support and reinforcement, it will lead to a mind set which will promote egalitarian outlook.

The unequal status of women in society is neither a legacy of the past not it is culture specific. But it is a result of complex operations of economics, political, psychological, social and cultural factors. Therefore, the economic role alone is inadequate in liberating women. What we really need is a total transformation of the social order through planned intervention. 


\section{Bibliography}

1. Afshar, Haleth, Women - Development and Survival in the Third World, Longman Singapore Publishers, Singapore.

2. Aganwal, C.M., Dimensions of Indian Womanhood, Shri Almora Book Depot, Almora, India, 1993.

3. Andiappan, P., Women and Work, Somaiya Publications, Bombay, 1980.

4. Blood, Robert O. and Hamblin, Robert L, "The Effects of the Wife's Employment on the Family Power Structure" published in The Family, by Bell N Wand Vogel EF, The Free Press, New York, 1968.

5. Cain, G G, Married Women in the Labour Force: An Economic Analysis University of Chicago Press, Chicago, 1964.

6. Delamant, Sara, The Sociology of Women - An Introduction, George Allen and Unwin Ltd., New York, 1980.

7. Desai, Neera, and Patel, Vibuthi (eds.), Indian Women: Change and Challenge in the International Decade, Gibson Printing Works, New Delhi, 1985.

8. Feldman, Francis, Lomas, Work in the Lives of Married Women, National Manpower Council, Columbia University Press, New York, 1958.

9. Ghadially, Rehana (ed.), Women in Indian Society, Sage Publications, New Delhi, 1988.

10. Ghosh, S K, Women in a Changing Society, S B Nangia, New Delhi, 1984.

11. Goode, William K, The Family, Prentice Hall of India Pvt. Ltd., New Delhi, 1965.

12. Gothoskar, Sujatha (ed.), Struggles of Women at Work, Vikas Publishing House, Delhi, 1992.

13. Jaiswal, R P, Professional Status of Women, Rawat Publicatons, Jaipur, 1993.

14. Maurya Sanab Deen, Women in India. Chaugh Publications, Allahabad, 1988, Meiss, Maria, Indian Women and Patriarchy, Concept, New Delhi, 1980.

15. Parikh, Indira J. and Gazg Pulin, K, Indian Women, An Inner Dialogue, Sage Publications, New Delhi, 1989.

16. Ramu G.N., Women Work and marriage in urban India, Sage Publications, New Delhi, 1989.

17. Swarajyalaxmi, C., Women at work, Discovery Publishing House, New Delhi, 1992. 